\title{
Missed opportunities of poor implementation of prevention with positives among HIV-positive women on treatment in Ekiti State, Southwest Nigeria
}

\begin{abstract}
Introduction: The current prevalence of HIV particularly in Nigeria does not reflect global efforts at curtailing the pandemic. One of the drivers increasing the rate of a new infection is the transmission of HIV by people already living with the virus. Scaling up prevention interventions and strategies will reverse this unwarranted trend.

Method: A cross-sectional study was carried out among women living with HIV (WLHIV) receiving care at the Adult Antiretroviral Clinic (ART) of the Ekiti State University Teaching Hospital, Ado-Ekiti between February and April 2021

Results: One hundred and forty-eight eligible WLHIV participated and completed the study. The majority of the participants were married $(74.3 \%)$, in a monogamous family setting $(68.9 \%)$, within the reproductive age group (91.8\%), and were Christians $(75.7 \%)$. Only 5.4\% earned all the components of prevention interventions and strategies for people living with HIV (PwP) leaving a wide gap of 94.6\% missed opportunities.

Conclusion: The findings that WLHIV in this study are well literate about HIV risk transmission and prevention strategies and are adherent to their HAART medications did not translate to the adequate observance of prevention interventions and strategies. Scaling up prevention with positive programs $(\mathrm{PwP})$ is urgently needed to prevent the further surge in the rate of new infections.
\end{abstract}

Keywords: HIV, prevention with positives, missed opportunities
Volume I2 Issue 4 - 202I

\author{
Idowu Pius Ade-Ojo,' Temitope Omoladun \\ Okunola,' Olufunke Temiloluwa Oso² \\ 'Department of Obstetrics Gynecology, Ekiti State University, \\ Nigeria \\ ${ }^{2}$ Department of Obstetrics and Gynecology, Ekiti State \\ University Teaching Hospital, Nigeria
}

\begin{abstract}
Correspondence: Idowu Pius Ade-Ojo, MB; BS, FWACS, FMCOG, Department of Obstetrics Gynecology, Ekiti State University, Ado-Ekiti, Nigeria, Tel +2348033886173, Email ipadeojo@eksu.edu.ng
\end{abstract}

Received: July 31, 202I | Published: August 17, 2021

\section{Introduction}

HIV/AIDS poses the main challenge to public health. An estimated $37.6(30.2-45)$ million people are presently known to be living with HIV/AIDS worldwide. ${ }^{1-3}$ Generally, struggles to prevent human immunodeficiency virus (HIV) infection have concentrated on reducing the risk of HIV infection among people who are HIV negative. . $^{1,45}$ However, in recent times, there have been scale-ups of HIV testing, antiretroviral therapy (ART) availability, and improved care globally. As a result, more people living with HIV are living longer and better lives and this has brought a new task of meeting the HIV prevention needs of individuals living with HIV. ${ }^{5,6}$ It has been identified that continued dependence on general HIV prevention campaigns may limit the efficacy and sophistication of prevention strategies, it may be more resourceful to change behaviors among fewer HIV positive people than many HIV negative individuals because unlike those who are HIV negative, they play a vital role in preventing new HIV infections, hence, the need for the introduction of positive prevention. ${ }^{6,7}$

Positive prevention also referred to as 'prevention with positives' can be defined as a set of approaches that help people living with HIV to live longer and healthier lives. ${ }^{8}$ It is essential for both public health and human rights perspectives. It embraces a set of core features that help people living with HIV to: protect their sexual and reproductive health and avoid other sexually transmitted infections (STIs); slow HIV disease progression; and promote shared responsibility to protect their sexual health and reduce the risk of HIV transmission. ${ }^{8-10}$ Basic approaches to prevention by people living with HIV consist of health promotion, patients' sexual risk behaviors, partners' status and disclosure, signs and symptoms of sexually transmitted infections and other opportunistic infections, reproductive health, and family planning interventions. ${ }^{11-13}$ Others are access to HIV, and sexual and reproductive health services, advocacy, community participation, and policy change. ${ }^{9,10,11,12}$

Although, it's been very successful in the United States of America, ${ }^{14,15}$ it is, unfortunately, being ignored by health care providers, governments, and program managers in Nigeria. ${ }^{16}$ Resources and efforts have been focused on the prevention of new HIV infections. Also, people living with HIV do not essentially recognize their prevention needs, as treatment has been seen as more vital. ${ }^{17}$ There is scarcity of studies about prevention with positives in developing countries. This study aimed to describe the practice of prevention with positives among HIV-positive women in Ekiti State, Nigeria. This will create awareness among people living with HIV, health care providers, and policymakers and engenders interventions that will promote positive prevention in the developing countries where there is a huge burden of HIV.

\section{Methods}

We carried out this cross-sectional study at the Adult Antiretroviral Clinic (ART) of Ekiti State University Teaching Hospital, Ado Ekiti, Ekiti State between February 2021 and April 2021. The ART clinic is one of the clinics in Ekiti State, Nigeria that provides comprehensive treatment for HIV-positive individuals in Ekiti State and its environments. The sample size was calculated using $0.2 \%$ 
prevalence obtained in Ekiti State by the 2012 National HIV \& AIDS and Reproductive Health Survey. ${ }^{18}$ Ethical clearance was obtained from the Ethics and Research Committee of Ekiti State University Teaching Hospital, Ado Ekiti, Ekiti State; and informed consent was obtained from all participants. Systematic random sampling was used to select the participants. The first client out of every 3 was counseled. Inclusion criteria for the study were HIV-positive women on Highly Active Antiretroviral Drugs, aged 18 years and above who gave consent while exclusion criteria were severe medical illness or mental illness, and refusal to give consent. Out of 160 clients counseled, 148 agreed and gave consent for the study.

Self-administered questionnaires were administered to the participants. Questionnaires were made up of a biodata section that

Table I Sociodemographic characteristics of participants described their age, marital status, type of marriage, employment status, religion, and place of residence. The second section was about prevention with positive practices like partner disclosure, use of the condom, sharing of sharp objects, knowledge about contracting other strains of HIV, pap smear, family planning services, and others. Data obtained was analyzed using Statistical Package for Social Sciences version 25. Data are presented in frequency and percentages.

\section{Results}

During this study, 148 women participated and completed the study. The sociodemographic characteristics were depicted in Table 1. The majority were in the reproductive age group. (Table 1) Most were in monogamous relationships. (Table 1) Most participants were Christians and of the Yoruba ethnic group.

\begin{tabular}{|c|c|c|}
\hline Characteristics & Frequency & Percentage (\%) \\
\hline \multicolumn{3}{|l|}{ Age } \\
\hline$<20$ years & 6 & 4.1 \\
\hline $20-24$ years & 12 & 8.1 \\
\hline $25-29$ years & 28 & 18.9 \\
\hline 30-34 years & 38 & 25.9 \\
\hline $35-40$ years & 36 & 24.9 \\
\hline $4 \mathrm{I}-44$ years & 14 & 9.5 \\
\hline $44-49$ years & 8 & 5.4 \\
\hline$\geq 50$ years & 6 & 4.1 \\
\hline \multicolumn{3}{|l|}{ Marital Status } \\
\hline Single & 26 & 17.6 \\
\hline Married & 110 & 74.3 \\
\hline Separated & 4 & 2.7 \\
\hline Divorced & 8 & 5.4 \\
\hline \multicolumn{3}{|l|}{ Type of marriage } \\
\hline Monogamy & 102 & 68.9 \\
\hline Serial monogamy & 20 & 13.5 \\
\hline Polygamy & 26 & 17.6 \\
\hline \multicolumn{3}{|l|}{ Religion } \\
\hline Christianity & 112 & 75.7 \\
\hline Islam & 24 & 23 \\
\hline None & 2 & 1.4 \\
\hline \multicolumn{3}{|l|}{ Tribe } \\
\hline Yoruba & 118 & 79.9 \\
\hline Igbo & 20 & 13.5 \\
\hline Hausa & 4 & 2.7 \\
\hline Others & 6 & 4.1 \\
\hline \multicolumn{3}{|l|}{ Residence } \\
\hline Urban & 86 & 58.1 \\
\hline Semi-urban & 12 & 8.1 \\
\hline Rural & 50 & 33.8 \\
\hline
\end{tabular}

Citation: Ade-Ojo IP, Okunola TO, Oso OT. Missed opportunities of poor implementation of prevention with positives among HIV-positive women on treatment in Ekiti State, Southwest Nigeria. Obstet Gynecol Int J. 202 1;12(4):269-273. DOI: I0. I5406/ogij.202 I.I2.00590 


\begin{tabular}{lll} 
Table Continued... & Frequency & Percentage (\%) \\
\hline Characteristics & 6 & \\
\hline Education & 10 & 4.1 \\
No formal education & 12 & 6.8 \\
Primary uncompleted & 28 & 8.1 \\
Primary completed & 5 & 18.9 \\
Secondary uncompleted & 18 & 6.8 \\
Secondary completed & 64 & 12.2 \\
Tertiary uncompleted & & 43.2 \\
Tertiary uncompleted & 92 & 62.2 \\
Occupation & 56 & 37.8 \\
Employed & &
\end{tabular}

Only 8 participants $(5.4 \%)$ practiced all the components of prevention with positives. (Figure 1) More than half were not using any family planning method despite being informed about its importance. Almost all participants (95.1\%) adhered to their medications while the majority were well educated about HIV transmission risk assessment and healthy living. (Figure 1) Two-thirds have disclosed their status to their partners while prevention practices like consistent use of condoms and avoidance of sharing sharp objects with others were being practiced by only $12.2 \%$. Thirty-one $(41.9 \%)$ had a Pap smear for cervical screening within the last year (Figure 1).

\section{Chart Title}

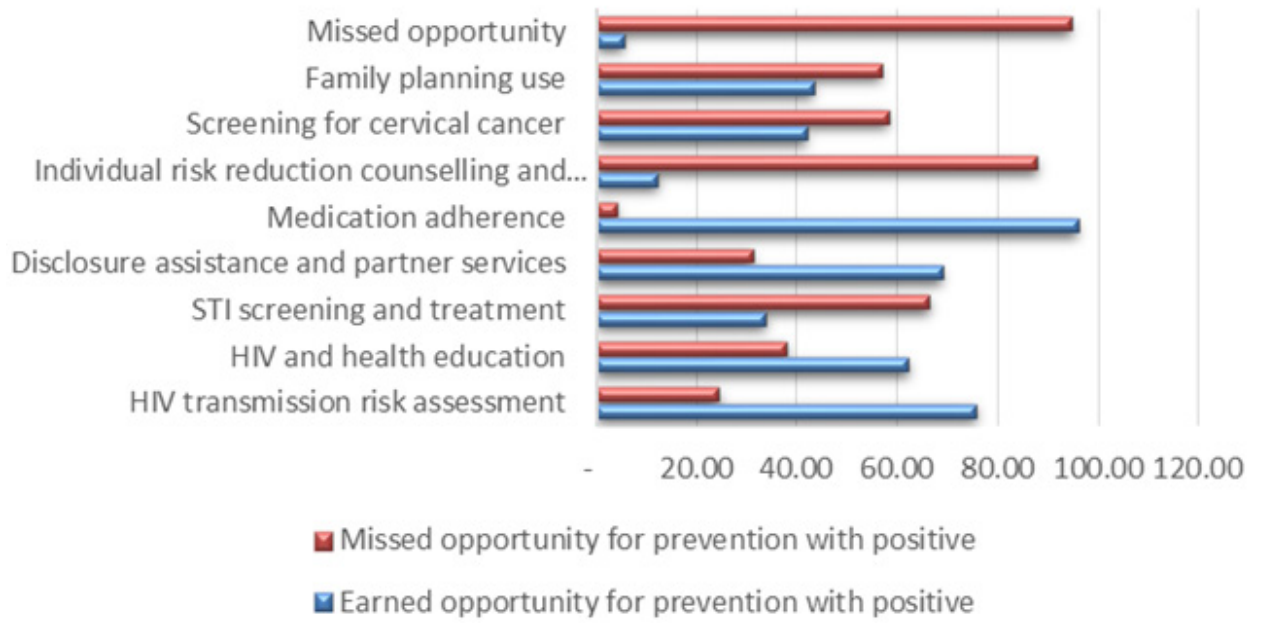

Figure I Showing the title chart of missed and earned opportunities of Prevention with Positives (PwP) in Ekiti State, southwest, Nigeria.

\section{Discussion}

This study examined the three pillars of HIV prevention with positives (PWP); protecting sexual and reproductive health and avoidance of sexually transmitted infections (STIs), Delay HIV disease progression, and promotion of shared responsibility to protect sexual health and reduce the risk of HIV transmission to others. To properly investigate these three pillars among our study population, our study tool addressed seven areas of prevention interventions and strategies; HIV transmission risk assessment, HIV and health education, STI screening and treatment, Disclosure assistance and partner services, Medication adherence, Individual risk reduction, and prevention practices, Screening for cervical cancer and Family planning use.
The majority of the women that participated in the study were in the reproductive age group between 25-40years. Most participants were in monogamous relationships, Christians, and of Yoruba ethnic group. This is a reflection of what is obtainable in the environment where this study was carried out.

At baseline, a good number (75.7\%) of the respondents had sound knowledge on HIV transmission risk assessment with the majority $66.2 \%$ being well equipped with information about HIV and health education. These findings are higher than that seen in the country's National Reproductive Health Survey, where it was observed that correct knowledge on all routes of possible transmission and methods of prevention was $54 \%$ and $52.5 \%$ respectively. ${ }^{19}$ In a study carried out in Northcentral Nigeria among 318 People Living with HIV AIDS 
receiving care at a treatment clinic, a higher knowledge on possible means of transmission and prevention of HIV was seen. The study reported that overall; $77.7 \%$ of respondents had good knowledge of HIV and AIDS..$^{20}$ This study also revealed an impressive rate of medication adherence of $95.9 \%$ with relatively low missed opportunities $(4.1 \%)$. This finding is similar to a high adherence prevalence rate found in an earlier multicentre study from Ado-Ekiti metropolis, southwest Nigeria by Aduloju et al..$^{21}$

Thirty-one percent did not disclose their HIV status to their spouses. This number is high because of the negative effect on partner services. Studies have shown that Women may not disclose their status to their partners due to fear of violence or rejection. ${ }^{22,23} \mathrm{We}$ also found out that only $12.2 \%$ had been counseled on risk reduction and prevention practices. This can lead to the emergence of resistant strains of HIV and further increase the incidence of HIV, thereby counteracting the global and national 90-90-90 target of ending the HIV/AIDS epidemic by $2030 .{ }^{24}$

Despite the recommendation by the WHO that HIV screening should be done at enrolment, ${ }^{25}$ only $38.9 \% \%$ of participants in this study have had sexually transmitted infections (STI) screening and treatment. HIV-positive patients with STI co-infection are at risk of increased morbidity and mortality and can also lead to a rise in the incidence of HIV infection. ${ }^{26}$ Those who have been screened for cervical cancer were below half of the respondents. Meanwhile, HIVpositive females are at higher risk of abnormal Pap smears than HIVnegative women. ${ }^{27}$ Similarly, in this study, we found a high unmet need for family planning. Those using any form of family planning were also less than half. This is similar to studies from Malawi and Ethiopia where $51.2 \%$ and $30.2 \%$ used some forms of contraceptives. ${ }^{28,29}$ This will not promote adherence to PMTCT as it can cause an increase in mother-to-child transmission of HIV. ${ }^{30}$

In all, we did not see any change in the prevalence of missed opportunities in prevention strategies and interventions for women living with HIV for over three decades of the HIV epidemic in Nigeria. Only $5.4 \%$ of WLHIV earned all the opportunities of prevention with positives intervention and strategies. We recorded very high missed opportunities. Similar high but lower missed opportunities (60\%) had been documented for prevention continuum in a predominantly Black and Latino community in New York by Zucker et al. ${ }^{31}$ Also, in Ethiopia, Fetene and Feleke found $76.1 \%$ missed opportunities for earlier HIV testing and diagnosis among 425 study population..$^{32}$ On the contrary, in a study from a high resource setting where access to healthcare is unrestricted, missed opportunities for earlier diagnosis have been reduced to $14 \% .^{33}$

\section{Conclusion}

In sum, ART has afforded many HIV-positive people the opportunity to live a more normal and healthy lifespan. This situation provides service providers the possibility of promoting more aggressively a double message for HIV-positive individuals concerning HIV prevention: (1) the necessity to protect oneself from disease progression, coinfection, and superinfection and (2) the need to accept some social responsibility of not transmitting HIV to others. It is of utmost importance that HIV prevention for HIV-positive and HIV-negative persons alike be addressed more holistically than before. This will create awareness among people living with HIV, health care providers, and policymakers and prompts interventions that will promote positive prevention in the developing countries where there is an enormous burden of HIV.

\section{Acknowledgments}

None.

\section{Funding}

None.

\section{Conflicts of interest}

No potential conflicts of interest are reported by the authors.

\section{References}

1. World Health Organization. HIV/AIDS- Key facts 2020.

2. UNAIDS. Global HIV \& AIDS statistics - Fact sheet 2021 (Preliminary UNAIDS 2021 epidemiological estimates).

3. Avert. Global HIV and AIDS statistics. 2021

4. Public Health Agency of Canada. Population-specific HIV/AIDS status report: People living with HIV/AIDS. Ottawa: Public Health Agency of Canada; 2013.

5. Auerbach JD. Principles of positive prevention. JAIDS Journal of Acquired Immune Deficiency Syndromes. 2004;37:S122-S125.

6. Cahill S Valadéz R. Growing older with HIV/AIDS: new public health challenges. Am J Public Health. 2013;103(3):e7-15.

7. Bertozzi S, Padian NS, Wegbreit J, et al. HIV/AIDS Prevention and Treatment. In: Jamison DT, Breman JG, Measham AR, et al., editors. Disease control priorities in developing countries. 2nd edn. Washington (DC): The International Bank for Reconstruction and Development/The World Bank; 2006.

8. Gentilini M, Chieze F. Socioeconomic aspects of human immunodeficiency virus (HIV) infection in developing countries. Bull Acad Natl Med. 1990;174(8):1209-1219.

9. INP+, IPPF, FPA India. Positive prevention: prevention strategies for people living with HIV. 2010.

10. PLHIV in Jamaica. Positive health, dignity, and prevention: training modules for promoting leadership among persons living with HIV. Washington, DC: Futures Group, Health Policy Project; 2015.

11. CDC Fact Sheet. Proven HIV prevention methods. Centers for disease control and prevention. 2016.

12. CDC HIV. Protect others if you have HIV. Division of HIV/AIDS Prevention, National Center for HIV/AIDS, Viral Hepatitis, STD, and TB Prevention, Centers for Disease Control and Prevention. 2021.

13. Collins CB, Hearn KD, Whittier DN, et al. Implementing packaged HIVprevention interventions for HIV-positive individuals: considerations for clinic-based and community-based interventions. Public Health Rep. 2010;125 Suppl 1(Suppl 1):55-63.

14. Family Health International (FHI). Prevention for positives: a course module for healthcare professionals: facilitator's guide. 2007.

15. Rotheram-Borus MJ, Flannery D, Lester P, et al. Prevention for HIVpositive families. J Acquir Immune Defic Syndr. 2004;37 Suppl 2:S133S134.

16. Avert- global information and education on HIV and AIDS. HIV and AIDS in Nigeria. 2020.

17. Brault MA, Spiegelman D, Hargreaves J, et al. Treatment as prevention: concepts and challenges for reducing HIV incidence. $J$ Acquir Immune Defic Syndr. 2019;82 Suppl 2(2):S104-S112.

18. Federal Ministry of Health. National HIV \& AIDS and reproductive health survey. 2012 (NARHS Plus). 2013. 
19. Federal Ministry of Health (Nigeria), National Agency for the Control of AIDS (NACA) (Nigeria), National Bureau of Statistics (Nigeria), National Population Commission (NPC), Nigerian Institute of Medical Research, Society for Family Health (Nigeria), University College Hospital, Ibadan. Nigeria National HIV/AIDS and Reproductive Health Survey 2007.

20. Olowookere SA, Fatiregun AA, Adewole IF. Knowledge and attitudes regarding HIV/AIDS and antiretroviral therapy among patients at a Nigerian treatment clinic. J Infect Dev Ctries. 2012;6(11):809-816.

21. Aduloju, O, T Aduloju, I P Ade-Ojo, et al. Medication adherence in HIVpositive pregnant women on antiretroviral therapy attending antenatal clinics in Ado metropolis, south-west Nigeria: A multicentre study. South African Journal of Obstetrics and Gynaecology. 2020:65-70.

22. Holstad M, DiIorio C, Magowe MKM. Motivating HIV positive women to adhere to antiretroviral therapy and risk reduction behavior: the KHARMA Project. Online journal of issues in nursing. 2006.

23. Arrey AE, Bilsen J, Lacor P, et al. "It's my secret": fear of disclosure among sub-Saharan African migrant women living with HIV/AIDS in Belgium. Moore S, editor. PLoS ONE. 2015;10(3):e0119653.

24. Dennin RH. Current HIV prevention policies are jeopardizing the "end of aids" project: realities counteract liberal visions. WJA. 2017;07(02):138156.

25. World Health Organization, Department of HIV/AIDS, World Health Organization, Reproductive Health and Research, editors. Antiretroviral drugs for treating pregnant women and preventing HIV infection in infants: guidelines on care, treatment, and support for women living with HIV/AIDS and their children in resource-constrained settings. Geneva: Dept. of HIV/AIDS : Dept. of Reproductive Health and Research, World Health Organization; 2004.
26. Saha K, Firdaus R, Santra P, et al. Recent pattern of Co-infection amongst HIV seropositive individuals in tertiary care hospital, Kolkata. Virol J. 2011;8(1):116.

27. McKenzie ND, Kobetz EN, Hnatyszyn J, et al. Women with HIV are more commonly infected with non-16 and -18 high-risk HPV types. Gynecologic Oncology. 2010;116(3):572-577.

28. Chintsanya J. USAID DHS Working papers - Trends and Correlates of Contraceptive Use among Married Women in Malawi: Evidence from 2000-2010 Malawi Demographic and Health Surveys. 2013.

29. Alene KA, Atalell KA. Contraceptive use and method preference among HIV-positive women in Amhara region, Ethiopia. BMC Women's Health. 2018;18(1):97.

30. Guimarães MF, Lovero KL, de Avelar JG, et al. Review of the missed opportunities for the prevention of vertical transmission of HIV in Brazil. Clinics. 2019;74:e318.

31. Zucker J, Patterson B, Ellman T, et al. Missed opportunities for engagement in the prevention continuum in a predominantly Black and Latino community in New York City. AIDS Patient Care and STDs. 2018;32(11):432-437.

32. Fetene NW, Feleke AD. Missed opportunities for earlier HIV testing and diagnosis at the health facilities of Dessie town, North-East Ethiopia. BMC Public Health. 2010;10(1):362.

33. Nanditha NGA, St-Jean M, Tafessu H, et al. Missed opportunities for earlier diagnosis of HIV in British Columbia, Canada: A retrospective cohort study. Sued O, editor. PLoS ONE. 2019;14(3):e0214012. 